\title{
Abnormal Renal and Hepatic Glucose Metabolism in Type 2 Diabetes Mellitus
}

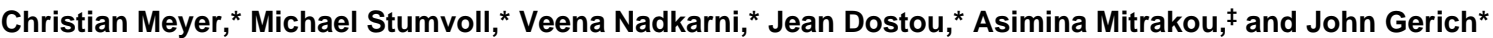 \\ *Departments of Medicine and Physiology and Pharmacology, University of Rochester School of Medicine, Rochester, New York 14642; \\ and ${ }^{\ddagger}$ Second Department of Internal Medicine Propadeutics, Evangelismas Hospital, University of Athens, Athens, Greece 10680
}

\begin{abstract}
Release of glucose by liver and kidney are both increased in diabetic animals. Although the overall release of glucose into the circulation is increased in humans with diabetes, excessive release of glucose by either their liver or kidney has not as yet been demonstrated. The present experiments were therefore undertaken to assess the relative contributions of hepatic and renal glucose release to the excessive glucose release found in type 2 diabetes. Using a combination of isotopic and balance techniques to determine total systemic glucose release and renal glucose release in postabsorptive type 2 diabetic subjects and age-weight-matched nondiabetic volunteers, their hepatic glucose release was then calculated as the difference between total systemic glucose release and renal glucose release. Renal glucose release was increased nearly $300 \%$ in diabetic subjects (321 \pm 36 vs. $125 \pm 15 \mu \mathrm{mol} / \mathrm{min}, P<0.001)$. Hepatic glucose release was increased $\sim 30 \%(P=0.03)$, but increments in hepatic and renal glucose release were comparable $(2.60 \pm 0.70$ vs. $2.21 \pm 0.32, \mu \mathrm{mol} \cdot \mathrm{kg}^{-1} \cdot \mathrm{min}^{-1}$, respectively, $\left.P=0.26\right)$. Renal glucose uptake was markedly increased in diabetic subjects (353 \pm 48 vs. $103 \pm 10 \mu \mathrm{mol} / \mathrm{min}, P<0.001)$, resulting in net renal glucose uptake in the diabetic subjects $(92 \pm 50 \mu \mathrm{mol} /$ min) versus a net output in the nondiabetic subjects $(21 \pm 14$ $\mu \mathrm{mol} / \mathrm{min}, P=0.043)$. Renal glucose uptake was inversely correlated with renal FFA uptake $(r=-0.51, P<0.01)$, which was reduced by $\sim 60 \%$ in diabetic subjects $(10.9 \pm 2.7$ vs. $27.0 \pm 3.3 \mu \mathrm{mol} / \mathrm{min}, P<0.002)$. We conclude that in type 2 diabetes, both liver and kidney contribute to glucose overproduction and that renal glucose uptake is markedly increased. The latter may suppress renal FFA uptake via a glucose-fatty acid cycle and explain the accumulation of glycogen commonly found in the diabetic kidney. (J. Clin. Invest. 1998. 102:619-624.) Key words: gluconeogenesis • kidney $\bullet$ liver $\bullet$ glucose production
\end{abstract}

\section{Introduction}

Excessive release of glucose into the circulation is a major factor responsible for fasting hyperglycemia in type 2 diabetes. This has generally been attributed exclusively to the liver (1, 2 ), since this organ had been thought to be the sole source of

Address correspondence to John E. Gerich, M.D., University of Rochester, 601 Elmwood Avenue, Box MED/CRC, Rochester, NY 14642. Phone: 716-275-5295; FAX: 716-461-4737.

Received for publication 6 December 1997 and accepted in revised form 28 May 1998.

J. Clin. Invest.

(C) The American Society for Clinical Investigation, Inc. 0021-9738/98/08/0619/06 \$2.00

Volume 102, Number 3, August 1998, 619-624

http://www.jci.org glucose in postabsorptive humans (3), and since increased hepatic glucose release had been found in diabetic animals $(4,5)$. However, increased renal glucose release has also been demonstrated in diabetic animals (6-9). Moreover, recent studies $(10,11)$ indicate that the human kidney may normally account for as much as $25 \%$ of postabsorptive glucose production. It is possible, therefore, that renal glucose release may contribute to the excessive glucose release in patients with type 2 diabetes.

Overall release of glucose into the systemic circulation is measured isotopically based on the dilution of the specific activity or enrichment of an infused isotope of glucose by release of endogenous unlabeled glucose (12). Liver and kidney can be considered the only organs capable of releasing glucose, since other tissues contain negligible activity of glucose-6-phosphatase (13). To assess their release of glucose, a combination of net balance and isotopic techniques must be used, because liver and kidney simultaneously take up and release glucose (12). With this approach, release of glucose by one of these organs is calculated as the difference between its glucose uptake (i.e., arterial glucose concentration $\times$ glucose fractional extraction $\times$ blood flow) and its net glucose balance (i.e., [arterial-venous glucose concentration] $\times$ blood flow $)(12,14)$ : The release of glucose by the other organ can then be calculated by subtraction from the simultaneously obtained overall isotopic rate of release of glucose into the circulation.

The measurement of net balance of glucose across an organ provides different information, namely, the difference between the uptake and release of glucose by that organ. It is possible, for example, that glucose uptake by an organ can exceed its glucose release so that there is net glucose uptake by the organ, while its release of unlabeled glucose contributes to the isotopically determined overall release of glucose into the systemic circulation. Thus net balance measurements may not necessarily reflect the contribution of an organ's release of glucose to overall systemic glucose release.

In the only study to our knowledge using the combined net balance-isotopic approach (hepatic venous catheter technique) to assess hepatic glucose release in type 2 diabetes (14), overall glucose release, but not hepatic glucose release, was significantly increased. Although these findings could be interpreted as providing evidence for increased renal glucose release in type 2 diabetes, it is possible that the failure to find increased hepatic glucose release was merely the result of the lack of sufficient statistical power due to the small number of subjects studied. Similar studies using this approach to directly assess renal glucose release in type 2 diabetes have not been reported.

These studies were therefore undertaken to evaluate the contribution of renal and hepatic glucose release to the increased overall glucose release found in type 2 diabetes. We used the combined isotopic-net balance approach (renal venous catheter technique) to determine overall glucose release and renal glucose release in subjects with type 2 diabetes and age-weight-matched nondiabetic volunteers and then calculated their hepatic glucose release as the difference between 
overall and renal glucose release. In addition, using a similar approach, we compared renal FFA and glucose uptake in our subjects. The increased plasma FFA concentrations found in type 2 diabetes have been proposed to result mainly from decreased FFA clearance (15-17). Since there appears to be a reciprocal relationship between renal glucose uptake and renal FFA uptake suggesting operation of a renal glucose-fatty acid cycle $(11,18,19)$, we hypothesized there was increased renal glucose uptake in patients with type 2 diabetes, as has been demonstrated in diabetic animals (20), and that this might suppress renal FFA uptake.

\section{Methods}

Subjects. Informed written consent was obtained from 15 nondiabetic volunteers (six men, nine women, $\mathrm{HbA}_{1 \mathrm{C}} 5.5 \pm 0.1 \%$ ) and 14 subjects with type 2 diabetes $\left(10\right.$ men, four women, $\mathrm{HbA}_{1 \mathrm{C}}$ $8.2 \pm 0.3 \%)$ of comparable age ( $43 \pm 3$ vs. $50 \pm 2 \mathrm{yr}, P=0.07)$ and body mass index $\left(27.8 \pm 1.1\right.$ vs. $\left.28.1 \pm 0.9 \mathrm{~kg} / \mathrm{m}^{2}, P=0.85\right)$. None of the diabetic subjects had been treated with insulin; those being treated with oral hypoglycemic agents had been withdrawn from their medication $4 \mathrm{~d}$ before the experiment. All diabetic subjects had no signs of nephropathy (i.e., no microalbuminuria) and subjects with coronary artery disease, proliferative retinopathy, or autonomic neuropathy were excluded. Nondiabetic volunteers had normal glucose tolerance tests according to World Health Organization criteria (21) and no family history of diabetes mellitus. Data of 10 of the 15 nondiabetic subjects have been included in a previous publication (11).

Protocol. Subjects were admitted to the University of Rochester General Clinical Research Center between 6:00 and 7:00 p.m. in the evening before experiments; they consumed a standard meal $(10 \mathrm{kcal} /$ $\mathrm{kg}, 50 \%$ carbohydrate, $35 \%$ fat, and $15 \%$ protein) between $7: 00$ and 8:00 p.m. and fasted overnight until experiments were completed.

At $\sim$ 5:30 a.m., an antecubital vein was cannulated and a primedcontinuous infusion of $\left[6^{-3} \mathrm{H}\right]$ glucose $(\sim 60-180 \mu \mathrm{Ci}, \sim 0.60 \mu \mathrm{Ci} /$ min; Amersham International, Amersham, UK) was begun. The bolus of $\left[{ }^{3} \mathrm{H}\right]$ glucose was adjusted for the prevailing hyperglycemia in the diabetic subjects $(\sim 60 \mu \mathrm{Ci} \times$ millimolar plasma glucose $/ 5 \mathrm{mM})$. For other studies to be reported separately, four of the nondiabetic volunteers and five of the diabetic subjects were also infused with $\left[{ }^{14} \mathrm{C}\right]$ glutamine and $\left[{ }^{13} \mathrm{C}\right]$ lactate. Between 8:00 and 9:00 a.m., a renal vein was catheterized under fluoroscopy and the position of the catheter tip was ascertained by injecting a small amount of iodinated contrast material. The catheter was then continuously infused with a saline solution (heparinized at $5.6 \mathrm{U} / \mathrm{min}$ ) to maintain patency. At $\sim 9$ 9:00 a.m., a continuous infusion of $\left[9,10^{-3} \mathrm{H}\right]$ palmitate $(0.15-0.25$ $\mu \mathrm{Ci} / \mathrm{min}$; Amersham International) was started in nine diabetic subjects and in 12 nondiabetic subjects. Shortly thereafter, a dorsal hand vein was cannulated and kept in a thermoregulated Plexiglass box at $65^{\circ} \mathrm{C}$ for sampling arterialized venous blood, and an antecubital venous infusion of $p$-aminohippuric acid $(12 \mathrm{mg} / \mathrm{min})$ was started for determination of renal blood flow. Starting at $\sim$ 10:00 a.m., three blood samples were collected simultaneously from the dorsal hand vein and the renal vein at 30-min intervals. Timed urine collections were made over $\sim 6 \mathrm{~h}$ from $\sim$ 5:30 a.m. to $\sim 11: 30$ a.m.

Analytical procedures. Blood samples were collected in oxalatefluoride tubes for glucose- and palmitate-specific activities and for glucose, FFA, lactate, alanine, glycerol, and $\beta$-hydroxybutyrate concentrations. Blood samples for insulin and glucagon concentrations were collected in EDTA tubes containing a protease inhibitor. Whole-blood glucose and urinary glucose were immediately determined in triplicate with a glucose analyzer (Yellow Springs Instrument Co., Yellow Springs, OH). Glucose determinations had a coefficient of variation of $0.9 \%$. For other determinations, blood samples were placed immediately in a $4^{\circ} \mathrm{C}$ ice bath, and plasma was separated within $30 \mathrm{~min}$ by centrifugation at $4^{\circ} \mathrm{C}$. Plasma $\left[6-{ }^{3} \mathrm{H}\right]$ glucose- and $\left[9,10-{ }^{3} \mathrm{H}\right]$ palmitate-specific activities and plasma FFA concentrations were determined by HPLC methods with coefficients of variation of $0.5,3.8$, and $2.3 \%$, respectively, as previously described (11). Plasma $p$-aminohippuric acid concentration was measured by a colorimetric method (22). Plasma lactate, alanine, glycerol, and $\beta$-hydroxybutyrate concentrations were measured by standard microfluorometric assays and plasma insulin and glucagon were measured by RIA as previously described (23-25).

Calculations. Systemic (total) release and uptake of glucose and palmitate were determined isotopically using standard steady-state equations (26), i.e., the infusion rate of the tracer in $\mathrm{dpm} \cdot \mathrm{kg}^{-1} \cdot \mathrm{min}^{-1}$ divided by the arterial tracer-specific activity in $\mathrm{dpm} \cdot \mu \mathrm{mol}^{-1}$. Since palmitate represents $30 \%$ of total plasma FFA (17), systemic palmitate release and uptake were divided by 0.3 to extrapolate data to total FFA. Systemic glucose and FFA clearance were calculated as their systemic uptake divided by their arterial concentration. Hepatic glucose release was calculated as the difference between total systemic glucose release and renal glucose release (see below).

Renal plasma flow (RPF) ${ }^{1}$ was determined by the $p$-aminohippuric acid clearance technique (22) and renal blood flow (RBF) was calculated as $\mathrm{RPF} /(1$ - hematocrit). Fractional extraction (FX) of glucose across the kidney was calculated as (arterial $\left[6^{-3} \mathrm{H}\right]$ glucosespecific activity $\times$ arterial glucose concentration - renal vein $\left[6^{-3} \mathrm{H}\right]$ glucose-specific activity $\times$ renal vein glucose concentration)/ (arterial $\left[6^{-3} \mathrm{H}\right]$ glucose-specific activity $\times$ arterial glucose concentration). Renal glucose uptake (RGU) was calculated as RBF $\times$ arterial glucose concentration $\times \mathrm{FX}-$ urinary glucose excretion. The latter was determined as urine volume $\times$ urine glucose concentration/urine collection period. Renal glucose net balance (RGNB) was calculated as $\mathrm{RBF} \times$ (arterial glucose concentration - renal vein glucose concentration). Renal glucose release was calculated as RGU - RGNB.

Analogous equations were used for FFA, lactate, alanine, glycerol, and $\beta$-hydroxybutyrate, except that RPF was used for FFA, alanine, glycerol, and $\beta$-hydroxybutyrate since organ exchange of these metabolites occurs via plasma. In addition, since arterial and renal venous palmitate-specific activities were not found to be significantly different in both diabetic and nondiabetic subjects, indicating no release into the circulation of FFA from renal stores, as has been previously found in humans (11) and dogs (27), FX of FFA was calculated as the difference in their arterial and renal venous concentrations divided by their arterial concentration.

Data analysis. Data are given as mean \pm SEM and were evaluated using nonpaired $t$ tests. Least-squares linear regression was used to assess correlations. A $P$ value $<0.05$ was considered statistically significant.

\section{Results}

Substrate and hormone concentrations and glucose- and palmitate-specific activities (Tables I and II). Arterial and venous concentrations and specific activities of glucose and FFA are given in Table I. Other substrate and hormone concentrations are given in Table II. Arterial glucose, FFA, and lactate concentrations were increased in the diabetic subjects, whereas there were no significant differences between the two groups in arterial alanine, glycerol, $\beta$-hydroxybutyrate, insulin or glucagon levels.

Systemic glucose and FFA fluxes (Figs. 1 and 2). Rates of systemic (total) glucose release (Fig. 1) were increased in diabetic subjects $\left(15.0 \pm 0.9\right.$ vs. $10.2 \pm 0.3 \mu \mathrm{mol} \cdot \mathrm{kg}^{-1} \cdot \mathrm{min}^{-1}$ in non-

1. Abbreviations used in this paper: FX, fractional extraction; RBF, renal blood flow; RGNB, renal glucose net balance; RGU, renal glucose uptake; RPF, renal plasma flow. 


\begin{tabular}{|c|c|c|c|c|}
\hline & $4.5 \mathrm{~h}^{*}$ & $5.0 \mathrm{~h}$ & $5.5 \mathrm{~h}$ & Mean \\
\hline \multicolumn{5}{|l|}{ RBF (liters/min) } \\
\hline Nondiabetic subjects & $1.33 \pm 0.07$ & $1.32 \pm 0.08$ & $1.31 \pm 0.08$ & $1.32 \pm 0.08$ \\
\hline Diabetic subjects & $1.39 \pm 0.10$ & $1.40 \pm 0.10$ & $1.35 \pm 0.10$ & $1.38 \pm 0.10$ \\
\hline \multicolumn{5}{|c|}{ Arterial glucose concentration (mM) } \\
\hline Nondiabetic subjects & $4.74 \pm 0.07$ & $4.65 \pm 0.06$ & $4.67 \pm 0.07$ & $4.69 \pm 0.07$ \\
\hline Diabetic subjects & $9.66 \pm 0.75$ & $9.68 \pm 0.76$ & $9.54 \pm 0.75$ & $9.63 \pm 0.75$ \\
\hline \multicolumn{5}{|c|}{ Renal vein glucose concentration (mM) } \\
\hline Nondiabetic subjects & $4.75 \pm 0.06$ & $4.68 \pm 0.07$ & $4.67 \pm 0.07$ & $4.71 \pm 0.07$ \\
\hline Diabetic subjects & $9.61 \pm 0.73$ & $9.63 \pm 0.74$ & $9.48 \pm 0.73$ & $9.57 \pm 0.73$ \\
\hline \multicolumn{5}{|c|}{ Arterial glucose-specific activity $(\mathrm{dpm} / \mu \mathrm{mol})$} \\
\hline Nondiabetic subjects & $1584 \pm 264$ & $1551 \pm 270$ & $1599 \pm 267$ & $1589 \pm 265$ \\
\hline Diabetic subjects & $1001 \pm 147$ & $1006 \pm 146$ & $1015 \pm 147$ & $1008 \pm 147$ \\
\hline \multicolumn{5}{|c|}{ Renal vein glucose-specific activity $(\mathrm{dpm} / \mu \mathrm{mol})$} \\
\hline Nondiabetic subjects & $1552 \pm 259$ & $1524 \pm 269$ & $1570 \pm 264$ & $1559 \pm 262$ \\
\hline Diabetic subjects & $970 \pm 141$ & $980 \pm 143$ & $989 \pm 142$ & $979 \pm 142$ \\
\hline \multicolumn{5}{|c|}{ Arterial FFA concentration $(\mu \mathrm{M})$} \\
\hline Nondiabetic subjects & $401 \pm 35$ & $380 \pm 34$ & $398 \pm 35$ & $399 \pm 35$ \\
\hline Diabetic subjects & $539 \pm 46$ & $533 \pm 45$ & $537 \pm 43$ & $536 \pm 44$ \\
\hline \multicolumn{5}{|c|}{ Renal vein FFA concentration $(\mu \mathrm{M})$} \\
\hline Nondiabetic subjects & $373 \pm 32$ & $348 \pm 31$ & $358 \pm 30$ & $365 \pm 31$ \\
\hline Diabetic subjects & $526 \pm 44$ & $520 \pm 44$ & $519 \pm 39$ & $522 \pm 42$ \\
\hline \multicolumn{5}{|c|}{ Arterial palmitate-specific activity $(\mathrm{dpm} / \mu \mathrm{mol})$} \\
\hline Nondiabetic subjects & $3348 \pm 278$ & $3290 \pm 303$ & $3372 \pm 307$ & $3332 \pm 289$ \\
\hline Diabetic subjects & $3138 \pm 387$ & $3175 \pm 391$ & $3186 \pm 388$ & $3166 \pm 387$ \\
\hline \multicolumn{5}{|c|}{ Renal vein palmitate-specific activity $(\mathrm{dpm} / \mu \mathrm{mol})$} \\
\hline Nondiabetic subjects & $3383 \pm 290$ & $3256 \pm 290$ & $3385 \pm 301$ & $3345 \pm 285$ \\
\hline Diabetic subjects & $3114 \pm 416$ & $3189 \pm 387$ & $3252 \pm 408$ & $3185 \pm 402$ \\
\hline
\end{tabular}

*Time after beginning tritiated glucose infusion.

diabetic volunteers, $P<0.001$, respectively) and their systemic glucose clearance was reduced $(1.63 \pm 0.10$ vs. $2.17 \pm 0.07$ $\mathrm{ml} \cdot \mathrm{kg}^{-1} \cdot \mathrm{min}^{-1}$ in nondiabetic volunteers, $\left.P<0.001\right)$. Systemic FFA release in the diabetic subjects was not significantly different from that of nondiabetic volunteers $(4.43 \pm 0.26$ vs. $\left.4.64 \pm 0.21, \mu \mathrm{mol} \cdot \mathrm{kg}^{-1} \cdot \mathrm{min}^{-1}, P=0.56\right)$, whereas their systemic FFA clearance was significantly reduced $(8.0 \pm 0.9$ vs. $13.9 \pm 1.6$ $\mathrm{ml} \cdot \mathrm{kg}^{-1} \cdot \mathrm{min}^{-1}, P=0.011$ ) (Fig. 2).

Renal substrate metabolism (Table III, Figs. 1 and 3). RBF $(1,369 \pm 103$ vs. $1,320 \pm 75 \mathrm{ml} / \mathrm{min}, P=0.72)$ and RPF $(831 \pm 62$ vs. $837 \pm 47 \mathrm{ml} / \mathrm{min}, P=0.95)$ flow were comparable in diabetic and nondiabetic subjects. (Table III).

RGNB was positive in the diabetic subjects (indicating net uptake) and negative in the nondiabetic volunteers (indicating

Table II. Arterial Substrate and Hormone Concentrations (Mean $\pm S E M$ )

\begin{tabular}{lccc}
\hline & $\begin{array}{c}\text { Nondiabetic } \\
\text { subjects }\end{array}$ & $\begin{array}{c}\text { Diabetic } \\
\text { subjects }\end{array}$ & $P$ \\
\hline Lactate $(\mu \mathrm{M})$ & $651 \pm 47$ & $1077 \pm 91$ & $<0.001$ \\
Glycerol $(\mu \mathrm{M})$ & $82 \pm 9$ & $82 \pm 7$ & 0.99 \\
Alanine $(\mu \mathrm{M})$ & $236 \pm 28$ & $280 \pm 29$ & 0.32 \\
$\beta$-Hydroxybutyrate $(\mu \mathrm{M})$ & $395 \pm 68$ & $588 \pm 159$ & 0.29 \\
Insulin $(\mathrm{pM})$ & $51 \pm 4$ & $60 \pm 6$ & 0.26 \\
Glucagon $(\mathrm{ng} /$ /iter $)$ & $84 \pm 8$ & $80 \pm 5$ & 0.71 \\
& & & \\
\hline
\end{tabular}

net output). Renal glucose release (Fig. 1) was increased nearly threefold in the diabetic subjects $(321 \pm 36$ vs. $125 \pm 15$ $\mu \mathrm{mol} / \mathrm{min}, P<0.001)$ and was correlated significantly with both arterial glucose concentration $(r=0.78, P<0.001)$ and systemic glucose release $(r=0.86, P<0.001$; Fig. 3$)$.

Urinary glucose excretion averaged $57.5 \pm 29.3$ and $1.6 \pm 0.4$ $\mu \mathrm{mol} / \mathrm{min}$, respectively, in diabetic and nondiabetic subjects $(P<0.001)$. RGU, which represented renal tissue glucose uptake since it was corrected for glycosuria, was markedly increased in the diabetic subjects $(353 \pm 48$ vs. $103 \pm 10 \mu \mathrm{mol} / \mathrm{min}$,

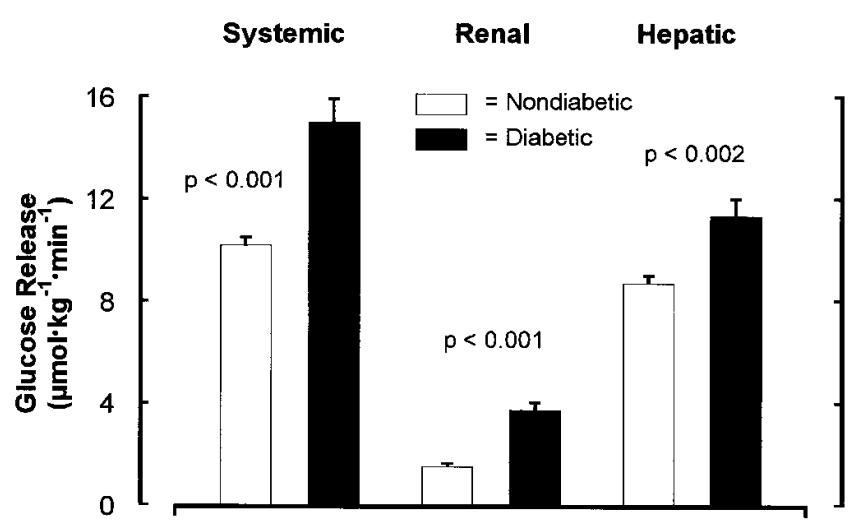

Figure 1. Systemic, renal, and hepatic glucose release in nondiabetic volunteers and diabetic subjects. Mean \pm SEM. 
FFA Turnover

FFA Clearance

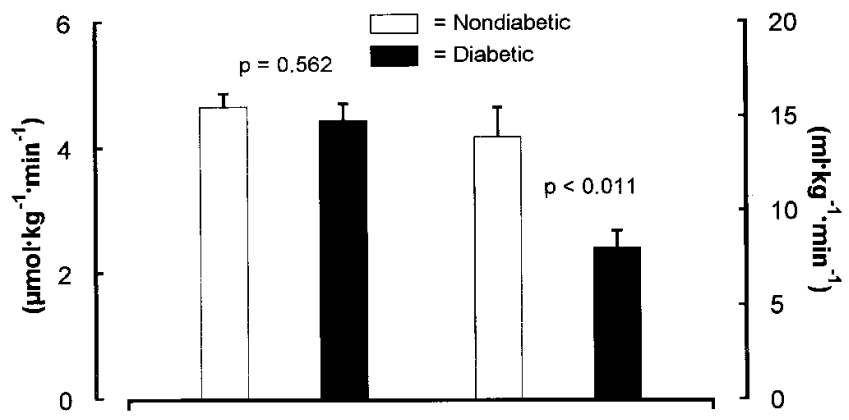

Figure 2. Systemic FFA turnover (release and disposal) and clearance in nondiabetic volunteers and diabetic subjects.

$P<0.001)$. This was not merely a consequence of hyperglycemia, since renal glucose FX was significantly greater in the diabetic subjects $(3.04 \pm 0.28$ vs. $1.72 \pm 0.16 \%, P<0.001)$.

In contrast, renal FFA FX and renal FFA uptake were both reduced $>60 \%$ in the diabetic subjects $(10.9 \pm 2.7$ vs. $27.0 \pm 3.3 \mu \mathrm{mol} / \mathrm{min}, P<0.002$, and $2.36 \pm 0.59$ vs. $8.12 \pm 0.62 \%$, $P<0.001)$. There was a significant inverse relationship between RGU and FFA uptake $(r=-0.51, P<0.01)$.

Although net renal lactate uptake was increased $\sim 50 \%$ in the diabetic subjects (Table II), this was not statistically significant. Net renal release of alanine was increased in the diabetic subjects $(16.5 \pm 3.5$ vs. $4.6 \pm 2.4 \mu \mathrm{mol} / \mathrm{min}, P=0.021)$. Net renal uptakes of glycerol and $\beta$-hydroxybutyrate were not significantly different between the groups.

Hepatic glucose release (Fig. 1). Since liver and kidney are the only organs capable of releasing free glucose into the circulation, hepatic glucose release was estimated as the difference between isotopically determined systemic (total) glucose release and renal glucose release. Calculated in this manner, hepatic glucose release was increased $\sim 30 \%$ in diabetic subjects (11.3 \pm 0.7 vs. $8.7 \pm 0.3 \mu \mathrm{mol} \cdot \mathrm{kg}^{-1} \cdot \mathrm{min}^{-1}, P=0.003$ ) (Fig. 1). Although the relative increase in renal glucose release was greater than that of hepatic glucose release ( $~ 300$ vs. $\sim 30 \%)$, the absolute increases in hepatic and renal glucose release were comparable $\left(2.60 \pm 0.70\right.$ vs. $2.21 \pm 0.32 \mu \mathrm{mol} \cdot \mathrm{kg}^{-1} \cdot \mathrm{min}^{-1}$, respectively, $P=0.26)$.

\section{Discussion}

These studies indicate that both hepatic and renal glucose release are increased in postabsorptive patients with type 2 diabetes and that the increments in glucose release by kidney
Table III. Renal Substrate Exchange (Mean \pm SEM)

\begin{tabular}{lccc}
\hline & $\begin{array}{c}\text { Non- } \\
\text { diabetic } \\
\text { subjects }\end{array}$ & $\begin{array}{c}\text { Diabetic } \\
\text { subjects }\end{array}$ & $P$ \\
\hline Glucose & & & \\
$\quad$ Arterial-Venous Difference $(\mu \mathrm{M})$ & $-14 \pm 11$ & $59 \pm 33$ & 0.051 \\
Net balance $(\mu \mathrm{mol} / \mathrm{min})$ & $-21 \pm 14$ & $92 \pm 50$ & 0.043 \\
Fractional extraction $(\%)$ & $1.7 \pm 0.2$ & $3.0 \pm 0.3$ & $<0.001$ \\
Uptake $(\mu \mathrm{mol} / \mathrm{min})$ & $103 \pm 10$ & $353 \pm 48$ & $<0.001$ \\
Release $(\mu \mathrm{mol} / \mathrm{min})$ & $125 \pm 16$ & $321 \pm 36$ & $<0.001$ \\
FFA & & & \\
Arterial-Venous Difference $(\mu \mathrm{M})$ & $34 \pm 4$ & $15 \pm 4$ & $<0.004$ \\
Fractional extraction $(\%)$ & $8.1 \pm 0.6$ & $2.4 \pm 0.6$ & $<0.001$ \\
Uptake $(\mu \mathrm{mol} / \mathrm{min})$ & $27 \pm 3$ & $11 \pm 3$ & $<0.002$ \\
Lactate & & & \\
Arterial-Venous Difference $(\mu \mathrm{M})$ & $128 \pm 13$ & $176 \pm 29$ & 0.16 \\
$\quad$ Net balance $(\mu \mathrm{mol} / \mathrm{min})$ & $105 \pm 9$ & $153 \pm 37$ & 0.22 \\
Glycerol & & & \\
Arterial-Venous Difference $(\mu \mathrm{M})$ & $44 \pm 4$ & $38 \pm 4$ & 0.37 \\
$\quad$ Net balance $(\mu \mathrm{mol} / \mathrm{min})$ & $35 \pm 3$ & $32 \pm 4$ & 0.58 \\
Alanine & & & \\
$\quad$ Arterial-Venous Difference $(\mu \mathrm{M})$ & $-6 \pm 3$ & $-19 \pm 3$ & 0.031 \\
$\quad$ Net balance $(\mu \mathrm{mol} / \mathrm{min})$ & $-5 \pm 2$ & $-17 \pm 3$ & 0.021 \\
$\beta$-Hydroxybutyrate & & & \\
Arterial-Venous Difference $(\mu \mathrm{M})$ & $27 \pm 9$ & $67 \pm 21$ & 0.10 \\
Net balance $(\mu \mathrm{mol} / \mathrm{min})$ & $21 \pm 9$ & $51 \pm 14$ & 0.09 \\
& & & \\
\hline
\end{tabular}

$\left(2.2 \pm 0.3 \mu \mathrm{mol} \cdot \mathrm{kg}^{-1} \cdot \mathrm{min}^{-1}\right)$ and liver $\left(2.6 \pm 0.7 \mu \mathrm{mol} \cdot \mathrm{kg}^{-1} \cdot \mathrm{min}^{-1}\right)$ are comparable. These results thus provide evidence that kidney and liver are of approximately equal importance for the excessive isotopically determined glucose release found in type 2 diabetes. Increases in both hepatic and renal glucose release have been previously demonstrated in diabetic animals (4-9), and thus our results are not necessarily unexpected. However, this appears to be the first demonstration in humans with type 2 diabetes, since a previous study using a similar approach failed to find increased hepatic glucose release (14).

Theoretically, the increase in renal glucose release in the diabetic subjects could have resulted from excessive detritiation of reabsorbed labeled glucose after its filtration at the glomerulus, since there was more glucose filtered and reabsorbed in the diabetic subjects. However, when normal volunteers have been infused with glucose, raising their plasma glucose to levels comparable to those of our diabetic subjects ( $\sim 12 \mathrm{mM}$ ), their systemic glucose release measured isotopically was suppressed to zero (28). This suggests that there is no detritiation of labeled glucose during its reabsorption from the
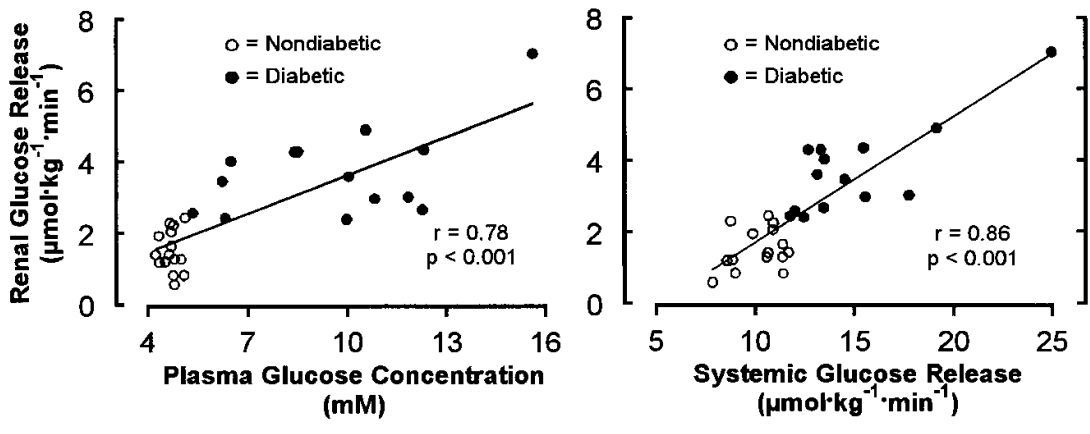

Figure 3. Correlation of renal glucose release with plasma glucose concentration and systemic glucose release in nondiabetic volunteers and diabetic subjects. 
renal tubule. Otherwise there would have been continued release of detritiated glucose into the circulation and the isotopically measured glucose appearance would not have been zero.

Since there was actual net renal uptake of glucose in our diabetic subjects, one could argue that the kidney made no net contribution to the overall increased release of glucose found in this condition. While this may be true, it should be pointed out that total systemic glucose release measured isotopically depends on dilution of the specific activity of the infused glucose tracer by release of unlabeled glucose by both liver and kidney regardless of the amount of glucose taken up by these organs, and had the kidney not released unlabeled glucose, total systemic glucose release would have been lower. Another way to consider the contribution of renal glucose release to the hyperglycemia in type 2 diabetes is as follows. At steady state, whole-body glucose release equals whole-body glucose uptake. If renal glucose release decreased in the diabetic subjects, whole-body glucose uptake would then exceed whole-body glucose release, and plasma glucose levels would fall. This in turn would cause, by simple mass action effects, whole-body glucose uptake to decrease until a new steady state would be established where again whole-body glucose release equaled whole-body glucose uptake.

Finally, and perhaps most importantly, the measurements of renal glucose release and uptake in the present study were made after establishment of hyperglycemia. It is difficult to extrapolate from this condition of steady-state hyperglycemia to the net effect of the kidney in the initiation of hyperglycemia. This depends on the rate of systemic glucose release exceeding the rate of systemic glucose uptake. To a certain extent, the increased renal glucose uptake found in our diabetic subjects depended on the mass action effects of hyperglycemia and the possible induction of glucose transporters by sustained hyperglycemia (see below). It is therefore possible that before establishment of hyperglycemia, renal glucose release might have exceeded renal glucose uptake. If such were the case, the kidney would have made a net contribution to the initiation of hyperglycemia.

There are several possible mechanisms that could explain the simultaneous increase in glucose release by liver and kidney. Increases in both hepatic and renal gluconeogenic enzyme activity have been found in experimental diabetic animals (2931 ) and presumably could also occur in humans. Insulin suppresses glucose release in both tissues $(1,32)$, and therefore the insulin resistance characteristically found in this condition $(1,2)$ could play a role. Moreover FFA, whose plasma concentrations are usually increased in type 2 diabetes (33), stimulate gluconeogenesis in both tissues $(34,35)$. Finally, in vitro studies indicate that increased availability of gluconeogenic substrates such as lactate would be expected to increase gluconeogenesis in both organs to a comparable extent (36).

Normally, renal glucose release in humans is largely if not exclusively attributable to gluconeogenesis (10). One would therefore expect increased renal glucose release in patients with type 2 diabetes to be mainly the result of increased gluconeogenesis. Nevertheless, we failed to find evidence for increased renal uptake of alanine and glycerol, and although renal lactate net uptake was increased by $50 \%$, this was not statistically significant. It should be noted, however, that these measurements represent net and not total renal uptake. An increase in lactate release resulting from glycolysis of the increased glucose taken up by the kidney could have masked an increase in lactate uptake. Furthermore, we did not determine renal uptake of glutamine, another important renal gluconeogenic precursor (37). Nevertheless, these observations raise the possibility that the increased renal glucose release found in patients with type 2 diabetes might have involved increased glycogenolysis.

The nondiabetic kidney contains little glycogen (38) and cells that do form glycogen lack glucose-6-phosphatase (39) and therefore can not release it as free glucose. However, it is well established that the diabetic kidney contains substantial glycogen and this occurs in cells capable of releasing it as free glucose (38). It is possible, therefore, that there might have been breakdown of this glycogen in our diabetic subjects, which contributed to their increased renal glucose release.

The demonstration in these studies of a hitherto unappreciated role of the kidney in overproduction of glucose in type 2 diabetes has several implications. It is possible that the reduced insulin requirements found in type 1 and type 2 diabetic patients with end-stage renal disease might involve reduced renal glucose release and not be solely attributable to reduced renal insulin clearance as is commonly thought (40). Moreover, reduced glucose release by the kidney might also explain the tendency for diabetic as well as nondiabetic patients with end-stage renal disease to develop hypoglycemia (41).

Previous studies have demonstrated increased renal glucose uptake in diabetic animals (20) and in humans with type 1 diabetes (42). In these studies renal glucose uptake was increased more than threefold in subjects with type 2 diabetes. It is noteworthy, however, that our subjects' increased renal glucose uptake was not merely due to the mass action effect of hyperglycemia. Their renal glucose fractional extraction was increased nearly twofold. This indicates more efficient renal uptake of glucose and could reflect induction of increased glucose transporters by hyperglycemia and increased hexokinase activity, which have been found in kidneys of diabetic animals $(20,43,44)$.

The increased renal glucose uptake found in the present studies in patients with type 2 diabetes and that observed previously in patients with type 1 diabetes (42) provides a possible explanation for the excessive renal glycogen accumulation found in humans with diabetes (38). It also has implications regarding the pathogenesis of diabetic nephropathy. Accumulation of extracellular matrix, considered to be of major importance (45), has been shown to be stimulated by high extracellular glucose concentrations (46) and by overexpression of Glut 1 transporters (47), suggesting that it may be dependent upon increased renal glucose uptake. Moreover, increased renal glucose uptake is associated with or could lead to activation of protein kinase $\mathrm{C}$ (48) and to enhancement of polyol pathway flux and nonenzymatic glycosylation of renal proteins (49), all of which may contribute to development of diabetic nephropathy.

Finally, although increased release of FFA from adipocytes is widely thought to occur in type 2 diabetes (50), these studies confirm previous observations (15-17) that systemic FFA release is not increased in this condition, but rather, that systemic FFA clearance is decreased. Furthermore, we found that renal FFA uptake and fractional extraction were markedly decreased in our patients and that there was an inverse relationship between renal FFA and glucose uptake. These observations suggest that increased renal glucose uptake may suppress renal FFA uptake in type 2 diabetes and provide further sup- 
port for the concept of a renal glucose fatty cycle in humans (11).

In conclusion, these studies provide evidence that in type 2 diabetes both renal and hepatic glucose release are increased to a comparable extent, thus implicating both organs as being important for the overproduction of glucose found in this condition. Our results also indicate that renal glucose uptake is markedly increased in type 2 diabetes. This could explain the accumulation of glycogen found in diabetic kidneys and may play a role in the development in diabetic nephropathy.

\section{Acknowledgments}

We wish to thank the staff of the General Clinical Research Center for their excellent technical help and Mary Little for her superb editorial support.

This work was supported in part by National Institutes of Health/ Division of Research Resources/General Clinical Research Center grants 5M01-RR 00044, NIDDK-20411, and 20579.

\section{References}

1. Dinneen, S., J. Gerich, and R. Rizza. 1992. Carbohydrate metabolism in noninsulin-dependent diabetes mellitus. N. Engl. J. Med. 327:707-713.

2. DeFronzo, R. 1988. The triumvirate: B-cell, muscle, and liver: a collusion responsible for NIDDM. Diabetes. 37:667-687.

3. Felig, P., and M. Bergman. 1995. The endocrine pancreas: Diabetes mellitus. In Endocrinology and Metabolism. P. Felig, J. Baxter, and L. Frohman, editors. McGraw-Hill, New York. 1107-1250.

4. Renold, A., C. Teng, F. Nesbett, and A. Hastings. 1953. Studies on carbohydrate metabolism in rat liver slices II: the effects of fasting and of hormonal deficiencies. J. Biol. Chem. 204:533-546.

5. Exton, J., S. Harper, A. Tucker, and R. Ho. 1973. Effects of insulin on gluconeogenesis and cyclic AMP levels in perfused livers from diabetic rats. Biochim. Biophys. Acta. 329:23-40.

6. Bearn, A., B. Billing, and S. Sherlock. 1951. Hepatic glucose output and hepatic insulin sensitivity in diabetes mellitus. Lancet. 1:698-701.

7. Carlsten, B., B. Hallgren, R. Jagenburg, A. Svanborg, and L. Werko. 1967. Arterio-hepatic venous differences of free fatty acids and amino acids. Acta. Med. Scand. 181:199-207.

8. Felig, P., J. Wahren, and R. Hendler. 1978. Influence of maturity-onset diabetes on splanchnic glucose balance after oral glucose ingestion. Diabetes. 27:121-126.

9. Waldhausl, W., P. Brotusch-Marrain, S. Gasic, A. Korn, and P. Nowotny. 1982. Insulin production rate, hepatic insulin retention and splanchnic metabolism after oral glucose ingestion in hyperinsulinemic type 2 (non-insulin-dependent) diabetes mellitus. Diabetologia. 23:6-15.

10. Stumvoll, M., U. Chintalapudi, G. Perriello, S. Welle, O. Gutierrez, and J. Gerich. 1995. Uptake and release of glucose by the human kidney: postabsorptive rates and responses to epinephrine. J. Clin. Invest. 96:2528-2533.

11. Meyer, C., V. Nadkarni, M. Stumvoll, and J. Gerich. 1997. Human kidney free fatty acid and glucose uptake: evidence for a renal glucose-fatty acid cycle. Am. J. Physiol. 273:E650-654.

12. Stumvoll, M., D. Overkamp, and J. Gerich. 1995. A primer on tracer methods for the study of glucose metabolism in man. Diab. Nutr. Metab. 8:298-314.

13. Weber, G., and A. Cantero. 1955. Glucose-6-phosphate activity in normal, precancerous, and neoplastic tissues. Cancer Res. 15:105-108.

14. DeFronzo, R., R. Gunnarsson, O. Bjorkman, M. Olsson, and J. Wahren. 1985. Effects of insulin on peripheral and splanchnic glucose metabolism in non-insulin-dependent (Type II) diabetes mellitus. J. Clin. Invest. 76:149-155.

15. Perriello, G., A. Mitrakou, B. Gumbiner, and J. Gerich. 1995. Nonesterified fatty acids in non-insulin-dependent diabetes: a critical update. Diabetes Annu. 7:91-106.

16. Taskinen, M., C. Bogardus, A. Kennedy, and B. Howard. 1985. Multiple disturbances of free fatty acid metabolism in non-insulin-dependent diabetes. $J$. Clin. Invest. 76:637-644.

17. Kelley, D., and J. Simoneau. 1994. Impaired free fatty acid utilization by skeletal muscle in non-insulin-dependent diabetes mellitus. J. Clin. Invest. 94: 2349-2356.

18. Lee, J., V. Vance, and G. Cahill. 1962. Metabolism of C14-labeled substrates by rabbit kidney cortex and medulla. Am. J. Physiol. 203:27-36.

19. Dzurik, R., and V. Chorvathova. 1972. Relation between the uptake of glucose and fatty acids by the rat kidney in vivo. Physiologia Bohemoslov. 21: $361-365$

20. Sochor, M., N. Baquer, and P. McLean. 1979. Glucose overutilization in diabetes: evidence from studies on the changes in hexokinase, the pentase phos- phate pathway, and glucuronate-xylulose pathway in rat kidney cortex in diabetes. Biochem. Biophys. Res. Commun. 32-39.

21. World Health Organization Expert Committee. 1980. Diabetes mellitus: a second report. Geneva, Switzerland. Technical Report Series. 646:1-80.

22. Brun, C. 1951. A rapid method for the determination of para-aminohippuric acid in kidney function tests. J. Lab. Clin. Med. 37:955-958.

23. Nurjhan, N., F. Kennedy, A. Consoli, C. Martin, J. Miles, and J. Gerich. 1988. Quantification of the glycolytic origin of plasma glycerol as an index of lipolysis in vivo. Metabolism. 37:371-377.

24. Consoli, A., N. Nurjhan, J. Reilly, D. Bier, and J. Gerich. 1990. Mechanism of increased gluconeogenesis in non-insulin-dependent diabetes mellitus: role of alterations in systemic, hepatic and muscle lactate and alanine metabolism. J. Clin. Invest. 86:2038-2045.

25. Miles, J., R. Rizza, M. Haymond, and J. Gerich. 1980. Effect of acute in sulin deficiency on glucose and ketone body turnover in man: evidence for the primacy of overproduction of glucose and ketone bodies in the genesis of diabetic ketoacidosis. Diabetes. 29:926-930.

26. Wolfe, R. 1992. Radioactive and Stable Isotope Tracers in Biomedicine: Principles and Practice of Kinetic Analysis. Wiley-Liss, New York.

27. Park, H., E. Leal-Pinto, M. MacLeod, and R. Pitts. 1974. $\mathrm{CO}_{2}$ production from plasma free fatty acids by the intact functioning kidney of the dog. Am. J. Physiol. 227:1192-1198.

28. DeFronzo, R., E. Ferrannini, R. Hendler, R. Felig, and J. Wahren. 1983. Regulation of splanchnic and peripheral glucose uptake by insulin and hyperglycemia in man. Diabetes. 32:35-45.

29. Lemieux, G., M. Aranda, P. Fournel, and C. Lemieux. 1984. Renal enzymes during experimental diabetes mellitus in the rat. Role of insulin, carbohydrate metabolism, and ketoacidosis. Can. J. Physiol. Pharmacol. 62:70-75.

30. Weber, G., M. Lea, H. Convery, and N. Stamm. 1967. Regulation of gluconeogenesis and glycolysis: studies of mechanisms controlling enzyme activity. Adv. Enzyme Reg. 5:257-298.

31. Mithieux, G., H. Vidal, C. Zitoun, N. Bruni, N. Daniele, and C. Minassean. 1996. Glucose-6-phosphatase mRNA and activity are increased to the same extent in kidney and liver of diabetic rats. Diabetes. 45:891-896.

32. Cersosimo, E., R. Judd, and J. Miles. 1994. Insulin regulation of renal glucose metabolism in conscious dogs. J. Clin. Invest. 93:2584-2589.

33. Bierman, E., V. Dole, and T. Roberts. 1957. An abnormality of nonesterified fatty acid metabolism in diabetes mellitus. Diabetes. 6:475-479.

34. Krebs, H., R. Speake, and R. Hems. 1965. Acceleration of renal gluconeogenesis by ketone bodies and fatty acids. Biochem. J. 94:712-720.

35. Williamson, J., R. Kreisberg, and P. Felts. 1966. Mechanism for the stimulation of gluconeogenesis by fatty acids in perfused rat liver. Proc. Natl. Acad. Sci. USA. 56:247-254.

36. Harmon, D., R. Britton, and R. Prior. 1984. In vitro rates of oxidation and gluconeogenesis from $\mathrm{L}(+)$ - and $\mathrm{D}(-)$ lactate in bovine tissues. Comp. Biochem. Physiol. 77B:365-368.

37. Wirthensohn, G., and W. Guder. 1986. Renal substrate metabolism. Physiol. Rev. 66:469-497.

38. Biava, C., A. Grossman, and M. West. 1966. Ultrastructural observations on renal glycogen in normal and pathologic human kidneys. Lab. Invest. 15:330-356.

39. Guder, W., and B. Ross. 1984. Enzyme distribution along the nephron. Kidney Int. 26:101-111.

40. Amico, J., and J. Klein. 1981. Diabetic management in patients with renal failure. Diabetes Care. 4:430-434.

41. Toth, E., and D. Lee. 1993. Spontaneous/uremic hypoglycemia is not a distinct entity: substantiation from a literature review. Nephron. 58:325-329.

42. Wahren, J., and P. Felig. 1975. Renal substrate exchange in human diabetes mellitus. Diabetes. 24:730-734.

43. Dominquez, J., K. Camp, L. Maianu, H. Feister, and T. Garvey. 1994. Molecular adaptations of glut 1 and glut 2 in renal proximal tubules of diabetic rats. Am. J. Physiol. F283-290.

44. Chin, E., A. Zamah, D. Landau, H. Gronbek, A. Flyvbjerg, D. LeRoith, and C. Bondy. 1997. Changes in facilitative glucose transporter messenger rebonucleic acid levels in the diabetic rat kidney. Endocrinology. 138:1267-1275.

45. Mauer, S., M. Steffes, E. Ellis, D. Sutherland, D. Brown, and F. Goetz. 1984. Structural-functional relationships in diabetic nephropathy. J. Clin. Invest. 74:1143-1155.

46. Danne, T., M. Spiro, and R. Spiro. 1993. Effects of high glucose on type IV collagen production by cultured glomerular epithelial, endothelial and mesangial cells. Diabetes. 42:170-177.

47. Heilig, C., L. Concipcion, B. Riser, S. Freytog, M. Zhu, and P. Corts. 1995. Overexpression of glucose transporters in rate mesangial cells cultured in a normal glucose milieu mimics the diabetic phenotype. J. Clin. Invest. 96:18021814.

48. Craven, P., and F. DeRubertis. 1989. Protein kinase C is activated in glomeruli from streptozotocin diabetic rats: possible mediation by glucose. $J$. Clin. Invest. 83:1667-1675.

49. Brownlee, M. 1992. Glycation products and the pathogenesis of diabetic complications. Diabetes Care. 15:1835-1843.

50. Reaven, G. 1995. The fourth musketeer-from Alexandre Dumas to Claude Bernard. Diabetologia. 38:3-13. 